\title{
RBEP
}

\section{O impacto do Programa de Inclusão Social da Universidade de São Paulo no acesso de estudantes de escola pública ao ensino superior público gratuito}

\author{
Mauricio dos Santos Matos \\ Selma Garrido Pimenta \\ Maria Isabel de Almeida \\ Maria Amélia de Campos Oliveira
}

\section{Resumo}

Analisa o impacto do Programa de Inclusão Social da Universidade de São Paulo (Inclusp) no acesso de estudantes de escola pública ao ensino superior público gratuito. Os dados foram coletados priorizando-se informações sobre renda, cor e outros aspectos de interesse relacionados aos candidatos oriundos de escola pública, em diferentes etapas do vestibular. Como resultado, foi observada a contribuição significativa do sistema de pontuação acrescida para o ingresso de estudantes de escola pública nos cursos de graduação da USP. Todavia, a contínua e intensa diminuição do percentual desses estudantes no vestibular tem contribuído para a diminuição do impacto das políticas de inclusão social implementadas, indicando a necessidade de maior aproximação entre a Universidade e as escolas públicas, bem como a ampliação das ações de inclusão social em desenvolvimento, visando reverter essa tendência.

Palavras-chave: inclusão social; acesso à educação superior; Universidade de São Paulo. 


\section{Abstract \\ The impact of the Social Inclusion Program of the University of São Paulo on the access of public school students to free public higher education}

The impact of the Social Inclusion Program of the University of São Paulo on the access of public school students to free public higher education was analyzed. The data were collected, prioritizing information about income, race and other aspects of interest related to public schools students in various stages of the vestibular. As a result, a significant contribution of the added scoring system for the inclusion of students from public schools was observed. However, the continuous and intense decrease in the percentage of public school students in the vestibular has contributed to the decrease the impact of social inclusion policies implemented, indicating the need for a more effective approximation between university and public schools, as well as the expansion of the social inclusion actions in development in order to revert this trend.

Keywords: social inclusion; access to higher education; University of Sao Paulo.

\section{Introdução}

Muitas pesquisas e reflexões sobre a temática da inclusão social têm sido desenvolvidas, focalizando discussões sobre o acesso à educação superior no Brasil (Pinto, 2004), a história das ações afirmativas (Moehlecke, 2002) e seu contexto histórico-ideológico (Guimarães, 2005), o sucesso escolar nos meios populares (Lahire, 1997) e as dificuldades do estudante em sua entrada na vida universitária (Coulon, 2008; Ezcurra, 2005, 2009).

Nos últimos anos, várias universidades públicas brasileiras têm se debruçado na elaboração de políticas afirmativas e programas de inclusão social, buscando corrigir a assimetria social existente entre a universidade e a sociedade. Nesse processo de elaboração e discussão, várias propostas têm sido delineadas, incorporando diferentes mecanismos de inclusão social baseados no estabelecimento de cotas para grupos sociais específicos, considerados excluídos, ou na atribuição de bônus (ou um conjunto de bônus) para esses grupos, de forma a beneficiá-los no processo do vestibular.

No contexto da Universidade de São Paulo (USP), alguns trabalhos têm sido publicados sobre o tema, refletindo sobre a trajetória escolar de seus estudantes (Oliveira, Souza, 2004) e sobre propostas 
institucionais de inclusão direcionadas à graduação (Pimenta, Almeida, Oliveira, 2010).

O Programa de Inclusão Social da USP (Inclusp) ${ }^{1}$ caracteriza-se como uma dessas propostas, concebido a partir da preocupação da Universidade com as barreiras socioculturais que dificultam o acesso e a permanência de jovens de segmentos menos favorecidos da sociedade aos cursos de graduação.

O jovem que tem acesso a uma educação de melhor qualidade tende a chegar ao vestibular mais bem preparado do que aquele que não teve a mesma oportunidade, vencendo, assim, a disputa por uma vaga na universidade. Já as famílias de menores faixas de renda têm na escola pública uma das poucas alternativas para a escolarização de seus filhos e é notória a deterioração da qualidade da educação pública no Brasil.

A grande maioria de estudantes do ensino médio (cerca de 85\%) cursa escolas públicas, mas, no momento do ingresso nas universidades públicas, essa proporção inverte-se. Em 2006, por exemplo, estudantes oriundos do ensino médio público representavam apenas $24,7 \%$ dos ingressantes na USP.

O egresso da escola pública tende a se sentir desestimulado a prestar o vestibular em razão de suas poucas chances de aprovação. Denota-se, portanto, que as condições socioeconômicas dos candidatos têm influência preponderante nas possibilidades de acesso à universidade.

Nesse contexto, a Universidade de São Paulo propôs o Inclusp, que tem por foco o estudante do ensino médio público. Seu objetivo principal é ampliar progressivamente o ingresso desses estudantes na USP, sem comprometer o critério de mérito acadêmico como legitimador desse processo.

Com o Inclusp, a Universidade de São Paulo busca contribuir para alterar esse quadro de exclusão social, atuando positivamente na superação das barreiras que dificultam o ingresso na Universidade, ampliando as possibilidades de acesso ao ensino superior e incentivando a continuidade dos estudos dos egressos de escola pública.

O Inclusp é um projeto de longo prazo que alcança o candidato ainda antes do vestibular, durante o ensino médio. Abrange o planejamento e a implementação de medidas de incentivo aos ingressantes para que permaneçam e concluam o curso, além de alterações no processo seletivo.

Como ação prevista para ser desenvolvida durante o vestibular, o Inclusp estabeleceu um sistema de pontuação acrescida, caracterizado por um acréscimo na pontuação obtida nas duas fases do vestibular pelo candidato que comprovasse ter cursado integralmente o ensino médio em escola pública no País. Em 2007 e 2008, um bônus de 3\% foi concedido a esses candidatos, com a diferença de que, em 2008, os candidatos poderiam optar por recebê-lo.

A aplicação do bônus já na primeira fase do vestibular mostra o esforço da USP em ampliar o contingente de estudantes do ensino médio público que irão concorrer à segunda fase, quando novamente receberão o bônus. Esse sistema, além de ampliar a possibilidade efetiva de ingresso,
${ }^{1}$ Aprovado no Conselho Universitário da Universidade de São Paulo em maio de 2006. O documento foi elaborado por professores e estudantes de unidades e grupos de pesquisa da USP e colaboradores externos: Selma Garrido Pimenta - pró-reitora de graduação - FE; Maria Amélia de C. Oliveira - EE; Maria Isabel de Almeida - FE; Antônio Joaquim Severino - FE; Antonio Luis de Campos Mariani - EP; Antonio Sérgio Alfredo Guimarães - FFLCH; Bernadete A. Gatti - Fundação Carlos Chagas; Bruno José S. de Melo - discente EEFE; Elba Siqueira de Sá Barretto - FE; Flávia Schilling - FE; Franco Maria Lajolo - vice-reitor FCF; Glaucius Oliva - IFSC; João Baptista B. Pereira - FFLCH; José Cippola Neto - ICB; Lucimar Rosa Dias - doutoranda - FE; Maria Thereza Fraga Rocco - Fuvest; Mauro Bertotti - IQ; Milton de Arruda Martins - FM; Moacyr Domingos Novelli - FO; Oswaldo Baffa Filho - FFCLRP; Patrícia Junqueira Grandino - EACH; Quirino Augusto de C. Carmello - ESALQ; Renato P. Morgado - discente ESALQ; Rosa Maria Fischer - FEA. 
ainda motiva aqueles que não o conseguiram a se prepararem para o próximo vestibular.

O bônus de 3\% foi mantido em 2008, de forma a possibilitar análises comparativas que pudessem ensejar modificações ou novas ações. No entanto, a análise dos resultados obtidos em 2007 e 2008 evidenciou a necessidade de aprofundamento das medidas previstas pelo Programa, o que foi aprovado pelo Conselho de Graduação da USP em sessão de 27 de março de 2008.

Assim, a partir de 2009, além do bônus de 3\%, concedido a todos os estudantes de escola pública, foram incluídos outros dois: um, de até 6\%, decorrente do desempenho desses estudantes no Exame Nacional do Ensino Médio (Enem); e outro, de até 3\%, qualificado pelo desempenho do estudante na prova do Programa de Avaliação Seriada da USP (Pasusp), aplicada a partir de 2008 somente para estudantes do $3^{\circ}$ ano do ensino médio público regular de escolas da Secretaria de Estado da Educação de São Paulo. Essas novas medidas permitiram aos estudantes oriundos de escola pública a possibilidade de alcançar um acréscimo significativo de até $12 \%$ em sua pontuação no vestibular da USP, a depender de seu desempenho nas provas do Enem e do Pasusp.

Nesse contexto, é de fundamental importância que seja feita uma análise mais criteriosa sobre os reflexos das diferentes ações promovidas pelo Inclusp, de forma a permitir o reconhecimento do real impacto do referido Programa para a inclusão social na USP. Neste artigo, assumiremos como foco de análise o impacto do sistema de pontuação acrescida no acesso de estudantes de escola pública aos cursos de graduação da USP, buscando caracterizar o perfil socioeconômico desses estudantes e outros aspectos de interesse.

\section{Detalhamento metodológico do processo de coleta e análise dos dados}

Para a análise do impacto do sistema de pontuação acrescida no vestibular, dados foram coletados junto à Fundação Universitária para o Vestibular (Fuvest) e à Pró-Reitoria de Graduação da Universidade de São Paulo (Gestão 2006-2010), priorizando-se informações do período de 2001 a 2010 relacionadas a duas importantes etapas do processo do vestibular: a inscrição e a convocação para matrícula na primeira chamada.

Na etapa de inscrição, a coleta de informações focalizou apenas o conjunto de candidatos inscritos no vestibular Fuvest em carreiras que possuíam cursos da Universidade de São Paulo, evitando-se incorporar informações de candidatos inscritos em carreiras que não contemplavam cursos USP. Também foram excluídos o conjunto de candidatos treineiros, já que estes, independentemente de sua performance no vestibular Fuvest, estavam impossibilitados de ingressar num curso superior por ainda não terem concluído o ensino médio.

A análise do perfil dos candidatos inscritos visou identificar a presença, em número absoluto e em percentual, dos diferentes perfis 
de estudantes da escola básica que buscam ingressar nos cursos da USP, bem como poder compreender possíveis relações entre a diminuição do número de inscrições de estudantes de escola pública no vestibular Fuvest e o percentual de ingresso desses estudantes na USP.

A análise da etapa de convocação para matrícula na primeira chamada da Fuvest permitiu a identificação do perfil dos candidatos que foram aprovados exclusivamente em razão da pontuação obtida no vestibular e também do impacto do bônus na classificação dos estudantes oriundos de escola pública. No entanto, para a análise do efeito do bônus, foi necessário comparar a situação real, na qual o bônus foi aplicado, com uma situação simulada, na qual a pontuação acrescida pela aplicação do bônus é desconsiderada.

A partir dessa comparação, foi possível determinar de forma quantitativa o conjunto de candidatos para os quais o bônus mostrou-se determinante para a sua aprovação no vestibular e, assim, estimar o impacto do bônus na ampliação do número de estudantes de escola pública na USP. No entanto, compreendemos que o impacto do bônus no vestibular Fuvest pode apresentar-se de forma muito mais complexa, produzindo efeitos qualitativos de difícil mensuração. Por exemplo, a simples divulgação da existência de um bônus para estudantes de escola pública, por si só, já pode ampliar o interesse desse grupo de estudantes em tentar concorrer a uma vaga na USP e, portanto, influenciar o processo do vestibular.

Além do conjunto de candidatos inscritos e convocados para matrícula na primeira lista de chamada da Fuvest, foi necessário definir o conjunto de estudantes que efetivamente ingressaram na USP, já que muitos candidatos aprovados acabam por não efetuar e confirmar a sua matrícula, cedendo sua vaga para outros candidatos. Na Universidade de São Paulo, o preenchimento das vagas não ocupadas é feito por meio da convocação de candidatos em listas de chamada publicadas pela Fuvest que respeitam a sequência de classificação dos candidatos no curso de interesse.

Assim, o conjunto real de estudantes que ingressa na USP é formado por aqueles que foram aprovados no vestibular Fuvest e que efetuaram e confirmaram a sua matrícula, caracterizando-se como o conjunto de referência para todas as análises sobre o percentual de ampliação de estudantes oriundos de escola pública na USP.

Neste artigo, a análise dos ingressantes foi realizada considerando-se o período de 2006 (ano que antecede a implantação do Inclusp e do sistema de pontuação acrescida) a 2009, priorizando-se a identificação do percentual de estudantes de escola pública no conjunto dos ingressantes na USP, bem como a caracterização desses estudantes em relação à escola pública onde concluíram o ensino médio e em relação a sua preparação em cursinhos pré-vestibulares. Buscou-se ainda analisar a distribuição desses estudantes nos diferentes cursos da USP, nas diferentes áreas do conhecimento e nos diferentes períodos de oferecimento dos cursos em que se matricularam.

Foram considerados estudantes de escola pública apenas os candidatos que cursaram integralmente o ensino médio público. A identificação desses 
estudantes no conjunto dos inscritos e dos convocados para matrícula na $1^{\mathrm{a}}$ chamada foi realizada mediante análise de um campo específico presente na ficha de inscrição, no qual declaravam ter realizado seus estudos integralmente no ensino médio público. Já para o conjunto dos ingressantes, a identificação dos estudantes oriundos de escola pública foi feita mediante a confirmação das informações declaradas na ficha de inscrição por meio da análise do histórico escolar entregue no ato de matrícula.

\section{O impacto do Inclusp no vestibular}

A USP vem ampliando continuamente o número de vagas, conforme mostrado na Tabela 1. No período de 2001 a 2010, houve um aumento expressivo de 44,44\% das vagas em decorrência da abertura de novos campi e da ampliação do número de cursos na USP.

Tabela 1 - Ampliação do Número de Vagas na USP - 2001-2010

\begin{tabular}{|c|c|}
\hline Ano & $\mathbf{N}^{\mathbf{o}}$ de Vagas \\
\hline 2001 & 7.354 \\
\hline 2002 & 7.811 \\
\hline 2003 & 8.331 \\
\hline 2004 & 8.547 \\
\hline 2005 & 9.567 \\
\hline 2006 & 9.952 \\
\hline 2007 & 10.202 \\
\hline 2008 & 10.302 \\
\hline 2009 & 10.557 \\
\hline
\end{tabular}

Fonte: Pró-Reitoria de Graduação da USP (Gestão 2006-2010).

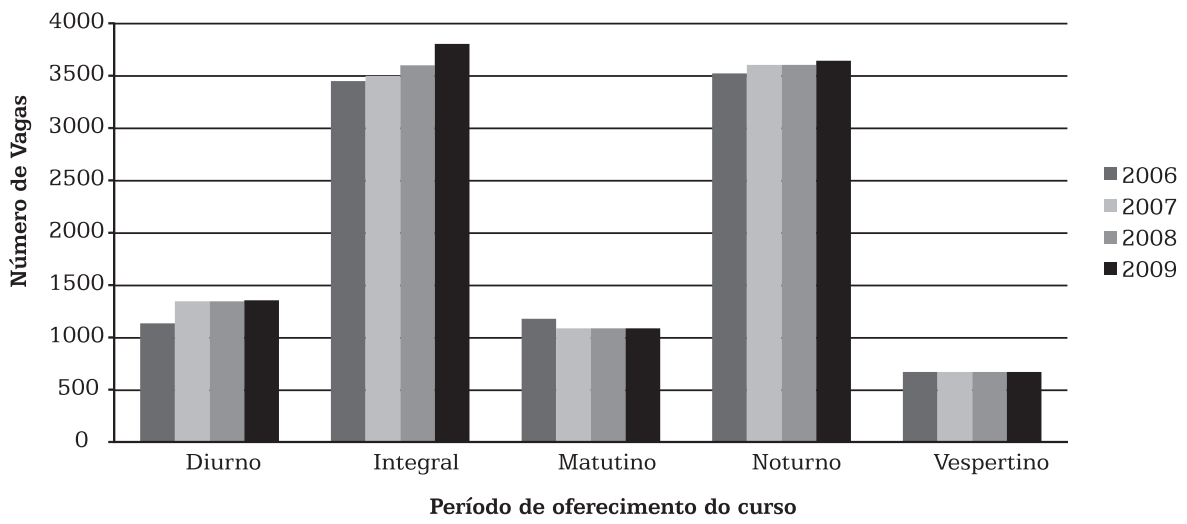

Gráfico 1 - Evolução do Número de Vagas na USP nos Diferentes Períodos de Oferecimento dos Cursos - 2006-2009

Fonte: Pró-Reitoria de Graduação da USP (Gestão 2006-2010). 
De 2006 a 2009, a ampliação de vagas na USP privilegiou a expansão contínua de cursos oferecidos em período integral e no noturno, conforme ilustrado no Gráfico 1, sem expansão de vagas em cursos vespertinos. A única ampliação significativa de vagas $(18,5 \%)$ ocorrida no período diurno ocorreu na transição do ano de 2006 para 2007, acompanhando um decréscimo de vagas no período matutino.

Até 2006, a ampliação de vagas na USP era acompanhada por aumento do número de inscrições no vestibular em carreiras com curso USP, como mostrado na Tabela 1. A partir de então, teve início uma trajetória de queda nas inscrições do vestibular Fuvest.

A análise dos dados do vestibular Fuvest permite compreender os condicionantes mais amplos do contexto social que interferem na diminuição geral dos inscritos nos vestibulares e, dentre eles, dos inscritos oriundos do ensino público. Como se percebe, com base nos dados da Fuvest mostrados na Tabela 2, o número de inscritos no vestibular para os cursos da USP caiu de 152.927 em 2006 para 125.998 em 2007, 123.476 em 2008, 122.472 em 2009 e 113.793 em 2010.

Tabela 2 - Número Total de Candidatos Inscritos no Vestibular Fuvest em Carreiras com Cursos USP, Desconsiderando-se os Treineiros - 2001-2010

\begin{tabular}{|c|c|}
\hline Ano & $\mathbf{N}^{\mathbf{o}}$ de candidatos inscritos \\
\hline 2001 & 120.498 \\
\hline 2002 & 122.806 \\
\hline 2003 & 134.793 \\
\hline 2004 & 135.851 \\
\hline 2005 & 136.789 \\
\hline 2006 & 152.927 \\
\hline 2007 & 125.998 \\
\hline 2009 & 123.476 \\
\hline 2010 & 122.472 \\
\hline
\end{tabular}

Fonte: Pró-Reitoria de Graduação da USP (Gestão 2006-2010).

Essa tendência de diminuição do número total de inscritos coincide com a diminuição da proporção de estudantes oriundos de escola pública em relação ao conjunto total de inscritos (Tabela 3). O número de inscritos oriundos do ensino público caiu de 68.998 em 2006 para 49.170 em 2007, 43.249 em 2008, 40.603 em 2009 e 30.273 em 2010. A diferença mais acentuada ocorreu de 2006 para 2007, quando houve uma queda de $28,74 \%$ nos inscritos oriundos do ensino público, enquanto que, de 2007 a 2008, a queda foi de 12,04\%. De 2008 a 2009, registrou-se uma queda menor de 6,12\%, o que poderia sinalizar uma possível interrupção futura dessa tendência de queda. No entanto, de 2009 a 2010 houve uma outra queda expressiva de $25,44 \%$, resultando numa diminuição de $56,12 \%$ do conjunto desses estudantes no período de 2006 a 2010. 
Tabela 3 - Percentual de Candidatos Oriundos de Escola Pública Inscritos em Carreiras com Cursos USP - 2001-2010

\begin{tabular}{|c|c|}
\hline Ano & Percentual (\%) \\
\hline 2001 & 36,54 \\
\hline 2002 & 37,25 \\
\hline 2003 & 38,36 \\
\hline 2004 & 37,76 \\
\hline 2005 & 42,09 \\
\hline 2006 & 45,12 \\
\hline 2007 & 39,02 \\
\hline 2008 & 35,03 \\
\hline 2009 & 33,15 \\
\hline 2010 & 26,60 \\
\hline
\end{tabular}

Fonte: Pró-Reitoria de Graduação da USP (Gestão 2006-2010).

Dos 113.793 inscritos em 2010, os estudantes de escola pública representaram 26,60\% (Tabela 3), a menor proporção do período analisado. Se considerarmos apenas o conjunto de candidatos presentes na $1^{\mathrm{a}}$ fase do vestibular Fuvest, o percentual diminui ainda mais (25,62\%), já que 2.876 candidatos de escola pública ausentaram-se na $1^{\mathrm{a}}$ fase do vestibular. Esse resultado evidencia a tendência de diminuição da presença de estudantes com esse percurso escolar nas inscrições para o vestibular da USP, a despeito de aproximadamente $85 \%$ dos estudantes cursarem o ensino médio em escolas públicas do Estado de São Paulo. Mesmo com a diminuição expressiva de estudantes de escola pública inscritos em carreiras com curso USP no vestibular de 2010, foi observado um aumento de 9,01\% no número de candidatos que fizeram o Pasusp e inscreveramse na Fuvest, o que legitima esse Programa na sua essência, que é a de aproximar a Universidade de São Paulo da escola pública, incentivando os estudantes a concorrerem a uma vaga na USP.

Entre as possíveis hipóteses para explicar a diminuição do número de candidatos no vestibular das universidades públicas paulistas, em especial os oriundos do ensino público, estão a criação de novos campi da Universidade Federal de São Paulo (Unifesp), em Guarulhos e Diadema, a criação da Universidade Federal do ABC (UFABC) e, principalmente, a corrida dos estudantes de ensino médio público ao programa de bolsas para o ensino superior privado concedidas pelo governo federal (Programa Universidade para Todos - ProUni) e a crescente valorização do Enem. A essas explicações soma-se a cultura de autoexclusão dos estudantes do ensino médio público em relação aos vestibulares das mais concorridas universidades públicas e o desconhecimento por parte desses jovens do sistema de ensino superior gratuito, ao qual têm direito.

Em oposição à tendência de queda observada nas inscrições no período de 2006 a 2010, a proporção de estudantes oriundos de escola pública no conjunto de estudantes que ingressam na USP mostrou um 
aumento significativo no período de 2006 a 2009, como mostrado na Tabela 4.

Assim, mais do que conter uma tendência de queda no percentual desses estudantes que ingressam na USP, as ações do Inclusp mostraram estar conseguindo reverter essa tendência. Prova disso é que, em 2009, a USP alcançou um nível histórico de estudantes de escola pública ingressantes em seus cursos, ultrapassando o percentual de 30\% (ver Tabela 4), mesmo dentro de um cenário bastante desfavorável, marcado por uma tendência de queda nas inscrições do vestibular de candidatos oriundos do ensino médio público, conforme já discutido e apresentado na Tabela 3. Esse aumento pode ser compreendido como reflexo direto do aperfeiçoamento do Inclusp no vestibular 2009, que ampliou as bonificações do sistema de pontuação acrescida.

Tabela 4 - Percentual de Ingressantes na USP que Cursaram todo o Ensino Médio em Escola Pública - 2001-2010

\begin{tabular}{|l|c|}
\hline Ano & Percentual (\%) \\
\hline 2001 & 25,7 \\
\hline 2002 & 25,2 \\
\hline 2003 & 26,8 \\
\hline 2004 & 25,5 \\
\hline 2005 & 26,7 \\
\hline 2006 & 24,7 \\
\hline 2007 & 26,7 \\
\hline 2008 & 26,3 \\
\hline 2009 & 30,1 \\
\hline 2010 & 25,6 \\
\hline Fonte: Pró-Reitoria de Graduação da USP (Gestão 2006-2010). \\
\hline \begin{tabular}{l} 
Obs.: Percentual calculado em relação ao número de vagas \\
efetivamente preenchidas em cada ano. \\
\hline
\end{tabular} \\
\hline
\end{tabular}

No entanto, os dados relativos ao conjunto de candidatos convocados para matrícula na $1^{\mathrm{a}}$ chamada em 2010 (Gráfico 2) sugerem mudança nessa tendência, confirmada pela análise dos dados da Tabela 4 relativos aos ingressantes desse ano, indicando um decréscimo no percentual de ingressantes oriundos da escola pública como reflexo da expressiva diminuição do número de candidatos do ensino médio público inscritos no vestibular da USP em 2010.

Nos quatro anos de implementação do Inclusp, o bônus teve papel determinante para a aprovação, em primeira chamada para matrícula, de 333 candidatos em 2007, 378 em 2008, 896 em 2009 e 559 em 2010 (Gráfico 2). Considerando o conjunto de todas as chamadas para matrícula, o bônus mostrou-se ainda mais determinante para o ingresso de estudantes de escola pública na USP, possibilitando o ingresso de 358 estudantes em 2007, 478 em 2008 e 953 em 2009 (Gráfico 3).

Os valores apresentados nos Gráficos 2 e 3 foram obtidos a partir da comparação entre a situação real, com o bônus, e a situação simulada, sem 
a aplicação do bônus. Calculou-se a diferença entre essas duas situações em relação ao conjunto de candidatos que responderam positivamente à questão da ficha de inscrição sobre a integralidade dos estudos no ensino médio público.

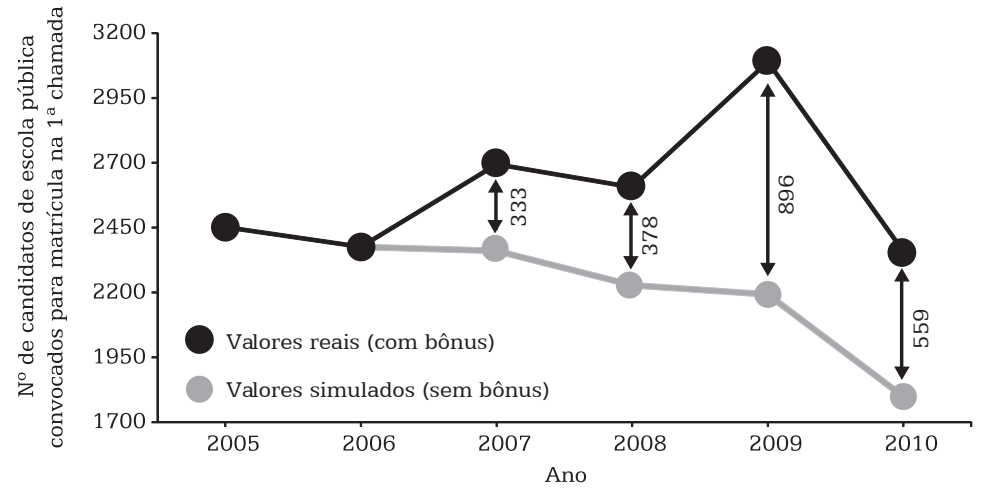

Gráfico 2 - Impacto do Sistema de Pontuação Acrescida na Ampliação do Número de Candidatos de Escola Pública Convocados para Matrícula na $1^{\mathrm{a}}$ Chamada - 2005-2010

Fonte: Pró-Reitoria de Graduação da USP (Gestão 2006-2010).

Obs.: Os valores expressos na vertical indicam a diferença em números absolutos.

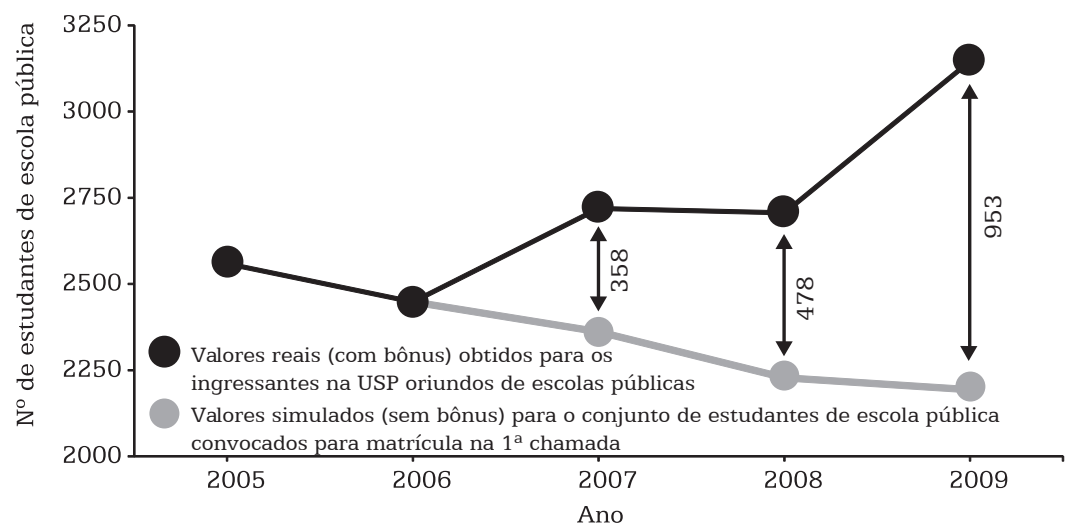

Gráfico 3 - Impacto do Sistema de Pontuação Acrescida na Ampliação do Número de Estudantes Ingressantes na USP Oriundos de Escola Pública 2005-2009

Fonte: Pró-Reitoria de Graduação da USP (Gestão 2006-2010).

Obs.: Os valores expressos na vertical indicam a diferença em números absolutos.

A análise dos dados apresentados no Gráfico 3 revelou que o bônus elevou, em números absolutos e percentuais, o total de ingressantes na USP provenientes do ensino médio público de 2.448 (24,7\%) em 2006 para 2.719 (26,7\%) em 2007. Em 2008, a análise dos dados referentes aos ingressantes revelou a presença de um total de 2.706 (26,3\%) ingressantes oriundos de escola pública.

A proximidade dos percentuais encontrados para os anos de 2007 e 2008 já era esperada, devido à manutenção, em 2008, do bônus em 3\% aplicado em 2007. Já em 2009, as simulações mostraram que, caso a USP não praticasse o sistema de pontuação acrescida, apenas 2.193 
estudantes oriundos de escola pública seriam convocados para matrícula na $1^{\text {a }}$ chamada, o que representaria um percentual de $20,77 \%$ desses candidatos em relação ao total de vagas disponíveis na USP. Porém, considerando a contribuição do conjunto de bônus praticado em 2009, o número de estudantes ingressantes oriundos do ensino médio público elevou-se para 3.146 (considerando-se todas as chamadas para matrícula) e o percentual alcançou 30,1\%, representando uma ampliação expressiva de 43,5\% (953 a mais) no número de candidatos de escola pública em relação à situação hipotética que desconsidera a aplicação do conjunto de bônus aplicado em 2009.

Assim, no período de 2007 a 2009, o bônus conteve a tendência de queda que vinha sendo observada no número de ingressantes do ensino público na USP, fazendo com que essa tendência se invertesse. Sem o sistema de pontuação acrescida, previsto no Inclusp, a tendência de queda observada nas inscrições no período de 2007 a 2009 teria se refletido em decréscimo ainda mais acentuado no número de ingressantes oriundos de escola pública, o que, de fato, não ocorreu nesse período.

No entanto, a análise dos dados relativos ao conjunto de candidatos convocados para matrícula na $1^{\text {a }}$ chamada em 2010 (Gráfico 2) e ingressantes (Tabela 4) mostra um decréscimo significativo no número de ingressantes oriundos de escola pública nesse ano, o que pode ser entendido como um reflexo direto da queda acentuada do número de inscrições desse perfil de estudante no vestibular Fuvest. Esses resultados refletem bem o alcance do sistema de pontuação acrescida que, mesmo mostrando ser um instrumento efetivo para a ampliação do ingresso de estudantes de escola pública na USP, o seu impacto tem sido cada vez mais reduzido devido à influência da contínua e intensa diminuição do número de inscrições desse conjunto de estudantes no vestibular Fuvest.

\section{Caracterização do perfil do estudante de escola pública que ingressa na USP}

Do conjunto de estudantes de escola pública que ingressaram na USP no período de 2006 a 2009, observa-se que mais da metade concluiu a educação básica em escola pública estadual paulista de ensino médio regular (Tabela 5) devido, principalmente, à presença em maior proporção de escolas públicas desse tipo em relação às demais.

Comparando-se 2009 com 2006 (ano que antecedeu a implantação do Inclusp), observa-se uma ampliação expressiva de 27,5\% no número de estudantes oriundos de escola pública estaduais paulistas de ensino médio regular, o que ilustra a contribuição do projeto no ingresso desses estudantes na USP.

Mesmo com a ampliação no número de estudantes de escola pública observada a partir de 2007 e a ampliação do sistema de bonificação em 2009, a distribuição percentual desses estudantes em relação ao tipo de escola pública onde concluíram o ensino médio apresentou pouca variação. 
Tabela 5 - Distribuição Percentual de Estudantes Ingressantes na USP em relação ao Tipo de Escola Pública onde Concluíram o Ensino Médio 2006-2009

\begin{tabular}{|c|c|c|c|c|c|c|}
\hline Ano & $\begin{array}{c}\text { Escolas } \\
\text { públicas } \\
\text { brasileiras } \\
\text { fora do } \\
\text { Estado de } \\
\text { São Paulo } \\
\text { (\%) }\end{array}$ & $\begin{array}{c}\text { Escolas } \\
\text { públicas } \\
\text { estaduais } \\
\text { paulistas } \\
\text { de Ensino } \\
\text { Médio } \\
\text { regular } \\
\text { (\%) }\end{array}$ & $\begin{array}{c}\text { Escolas } \\
\text { técnicas } \\
\text { estaduais } \\
\text { paulistas } \\
(\%)\end{array}$ & $\begin{array}{c}\text { Escolas } \\
\text { técnicas } \\
\text { federais } \\
(\%)\end{array}$ & $\begin{array}{c}\text { Escolas } \\
\text { municipais } \\
\text { paulistas } \\
\text { (\%) }\end{array}$ & $\begin{array}{c}\text { Não } \\
\text { definida } \\
(\%)\end{array}$ \\
\hline 2006 & 0 & 56,62 & 23,61 & 9,48 & 2,29 & 8,01 \\
\hline 2007 & 5,55 & 55,87 & 28,39 & 8,42 & 1,77 & 0 \\
\hline 2008 & 4,84 & 55,21 & 26,61 & 10,31 & 3,03 & 0 \\
\hline 2009 & 5,05 & 56,17 & 27,50 & 8,87 & 2,00 & 0,41 \\
\hline
\end{tabular}

Fonte: Pró-Reitoria de Graduação da USP (Gestão 2006-2010).

Esse resultado indica que o sistema de bonificação beneficiou igualmente todos os estudantes de escola pública, independentemente de sua escola pública de origem, quebrando o mito de que as escolas técnicas seriam as mais beneficiadas pelo sistema de pontuação acrescida, por possuírem estudantes supostamente mais bem preparados para o vestibular e para os quais o bônus contribuiria com acréscimos mais expressivos na pontuação, quando comparados aos acréscimos recebidos por estudantes de escolas públicas municipais e estaduais de ensino médio regular.

O percentual de ingressantes na USP oriundos de escola pública que frequentaram cursinhos pré-vestibulares é apresentado na Tabela 6.

Tabela 6 - Percentual de Ingressantes Oriundos de Escola Pública que Responderam a Questão $\mathbf{n}^{\circ} 9$ do Questionário Socioeconômico da Fuvest relativa a sua Preparação em Cursinhos Pré-Vestibulares - 2006-2009

\begin{tabular}{|c|c|c|c|c|c|c|c|}
\hline Ano & $\begin{array}{l}\text { Não } \\
\text { (\%) }\end{array}$ & $\begin{array}{c}\text { Sim, } \\
\text { menos } \\
\text { de um } \\
\text { semestre } \\
(\%)\end{array}$ & $\begin{array}{l}\text { Sim, um } \\
\text { semestre } \\
\text { completo } \\
\text { (\%) }\end{array}$ & $\begin{array}{c}\text { Sim, } \\
\text { de um } \\
\text { semestre } \\
\text { a um ano } \\
(\%)\end{array}$ & $\begin{array}{c}\text { Sim, de } \\
\text { um ano } \\
\text { a um } \\
\text { ano e } \\
\text { meio } \\
(\%)\end{array}$ & $\begin{array}{c}\text { Sim, de } \\
\text { um ano } \\
\text { e meio } \\
\text { a dois } \\
\text { anos } \\
(\%)\end{array}$ & $\begin{array}{c}\text { Sim, } \\
\text { mais } \\
\text { de dois } \\
\text { anos } \\
(\%)\end{array}$ \\
\hline 2006 & 22,60 & 8,06 & 5,98 & 29,39 & 9,82 & 13,10 & 11,05 \\
\hline 2007 & 25,61 & 9,04 & 6,97 & 30,76 & 8,34 & 10,71 & 8,56 \\
\hline 2008 & 26,36 & 8,51 & 6,95 & 30,37 & 9,26 & 11,00 & 7,55 \\
\hline 2009 & 23,27 & 9,06 & 6,64 & 28,79 & 9,58 & 12,64 & 10,02 \\
\hline
\end{tabular}

Fonte: Pró-Reitoria de Graduação da USP (Gestão 2006-2010).

Obs.: Percentual calculado em relação ao número de respostas válidas para a questão nº 9 do questionário socioeconômico da Fuvest assinaladas pelos candidatos ingressantes na USP oriundos de escola pública.

Observa-se que, no período de 2006 a 2009, praticamente 3/4 desses estudantes declararam ter frequentado cursinhos pré-vestibulares, o que sugere uma contribuição de uma preparação adicional pré-vestibular para 
a aprovação dos estudantes de escola pública na USP. No entanto, o fato de haver um percentual significativo (24,46\% em média) de estudantes de escola pública que ingressam na USP sem uma preparação em cursinhos pré-vestibulares, mostra que esse tipo de preparação complementar não é determinante para o ingresso desse perfil de estudante na USP e que uma boa formação na educação básica pode ser obtida em muitas escolas públicas de qualidade.

Analisando-se o período do curso no qual os estudantes de escola pública ingressaram (Tabela 7), observa-se que a ampliação no número desses estudantes no período de 2001 a 2009 ocorreu, sobretudo, por meio do seu ingresso em cursos oferecidos no período noturno. Do conjunto total desses estudantes, praticamente metade ingressou em cursos noturnos.

Tabela 7 - Distribuição Percentual do Conjunto de Ingressantes Oriundos do Ensino Médio Público nos Diferentes Períodos de Oferecimento do Curso no qual se Matricularam - 2006-2009

\begin{tabular}{|c|c|c|c|c|c|}
\hline Ano & $\begin{array}{c}\text { Diurno } \\
\text { (\%) }\end{array}$ & $\begin{array}{c}\text { Integral } \\
(\mathbf{\% )}\end{array}$ & $\begin{array}{c}\text { Matutino } \\
\mathbf{( \% )}\end{array}$ & $\begin{array}{c}\text { Noturno } \\
(\%)\end{array}$ & $\begin{array}{c}\text { Vespertino } \\
\mathbf{( \% )}\end{array}$ \\
\hline 2006 & 9,48 & 21,45 & 10,91 & 52,00 & 6,17 \\
\hline 2007 & 9,89 & 22,03 & 10,92 & 50,31 & 6,84 \\
\hline 2008 & 10,53 & 20,99 & 11,05 & 50,00 & 7,43 \\
\hline 2009 & 9,85 & 24,57 & 10,36 & 48,82 & 6,39 \\
\hline
\end{tabular}

Fonte: Pró-Reitoria de Graduação da USP (Gestão 2006-2010).

Obs.: Percentuais calculados em relação ao total de ingressantes na USP oriundos do ensino médio público em cada ano.

Tabela 8 - Percentual de Estudantes de Escola Pública que Ingressaram em Cursos Oferecidos no Período Noturno com a Intenção de Trabalhar durante seus Estudos Universitários - 2007-2009

\begin{tabular}{|c|c|}
\hline Ano & $\begin{array}{c}\text { Percentual } \\
\text { (\%) }\end{array}$ \\
\hline 2007 & 86,49 \\
\hline 2008 & 84,70 \\
\hline 2009 & 85,63 \\
\hline
\end{tabular}

Fonte: Pró-Reitoria de Graduação da USP (Gestão 2006-2010). Obs.: Percentual relativo ao número total de estudantes de escola pública ingressos em cursos noturnos que responderam a questão nº 21 do questionário socioeconômico da Fuvest.

Esses dados ilustram a importância desses cursos na inclusão de estudantes oriundos de escola pública, que acabam preferindo estudar no período noturno por possibilitar o desenvolvimento de atividades profissionais paralelamente aos estudos, conforme aponta a análise das informações declaradas pelos estudantes (Tabela 8) no questionário socioeconômico da Fuvest.

Em relação ao total de ingressantes (Tabela 9), verifica-se a ampliação na presença de estudantes de escola pública em todos os períodos. Comparando-se os dados de 2006 (ano que antecedeu a implantação do Inclusp) com os de 2009, observa-se um aumento de mais $8,14 \%$ no 
percentual de preenchimento de vagas no período matutino, seguido de um aumento de 8,08\% no período vespertino, 6,50\% no período noturno, $5,22 \%$ no período integral e 2,38\% no período diurno.

Tabela 9 - Distribuição Percentual do Conjunto de Vagas Preenchidas por Ingressantes Oriundos do Ensino Médio Público nos Diferentes Períodos de Oferecimento do Curso no qual se Matricularam - 2006-2009

\begin{tabular}{|c|c|c|c|c|c|}
\hline Ano & $\begin{array}{c}\text { Diurno } \\
\mathbf{( \% )}\end{array}$ & $\begin{array}{c}\text { Integral } \\
\mathbf{( \% )}\end{array}$ & $\begin{array}{c}\text { Matutino } \\
\mathbf{( \% )}\end{array}$ & $\begin{array}{c}\text { Noturno } \\
\mathbf{( \% )}\end{array}$ & $\begin{array}{c}\text { Vespertino } \\
\mathbf{( \% )}\end{array}$ \\
\hline 2006 & 20,53 & 15,22 & 22,67 & 36,07 & 22,47 \\
\hline 2007 & 20,09 & 17,17 & 27,30 & 37,97 & 27,76 \\
\hline 2008 & 21,19 & 15,77 & 27,61 & 37,52 & 30,00 \\
\hline 2009 & 22,91 & 20,44 & 30,81 & 42,57 & 30,55 \\
\hline
\end{tabular}

Fonte: Pró-Reitoria de Graduação da USP (Gestão 2006-2010).

Obs.: Percentuais calculados em relação ao número total de vagas preenchidas em cada ano.

A distribuição dos estudantes oriundos de escola pública que ingressaram na USP no período de 2006 a 2009 por área do conhecimento é apresentada no Gráfico 4. Nota-se que, mesmo com o Inclusp e a consequente ampliação do percentual de estudantes de escola pública na USP, há pouca variação na distribuição desses estudantes por área de conhecimento, havendo um ligeiro aumento nas áreas Biológicas e de Humanas e um pequeno decréscimo na área de Exatas.

Quando se considera a relação entre o número de vagas preenchidas por esse conjunto de estudantes e o total de vagas preenchidas em cada uma das áreas do conhecimento (Gráfico 5), percebe-se que houve ocupação maior das vagas nas áreas de Humanas e Exatas. Comparando-se o ano de 2009 com o ano de 2006 (antes do Inclusp), verifica-se um aumento de 8,1\% na ocupação de vagas por ingressantes de escola pública na área de Humanas, 7,0\% na área de Biológicas e 0,9\% na área de Exatas.

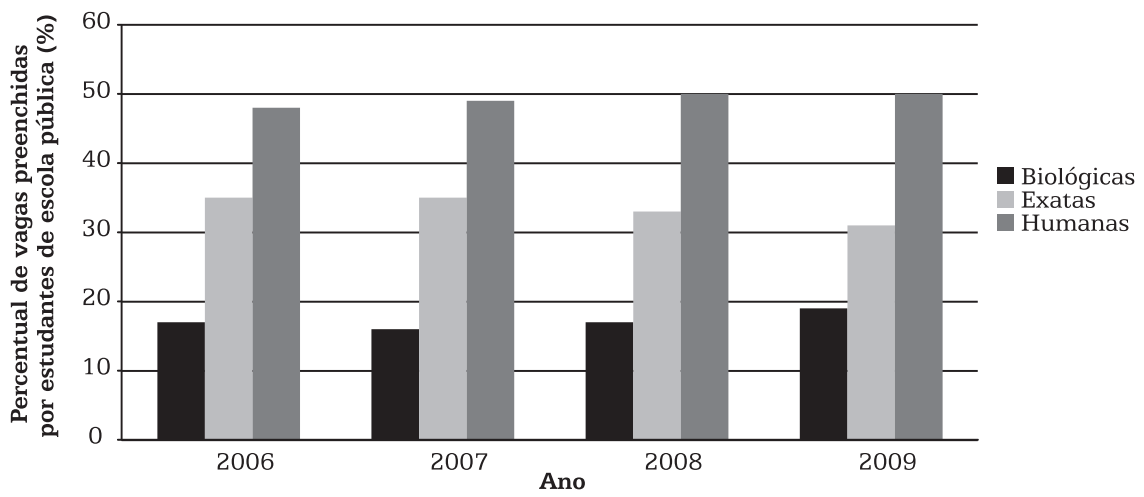

Gráfico 4 - Comparação entre os Percentuais de Vagas Preenchidas por Estudantes de Escola Pública em cada uma das Áreas do Conhecimento Valores Calculados em relação ao Número de Vagas Preenchidas por esses Estudantes - 2006-2009

Fonte: Pró-Reitoria de Graduação da USP (Gestão 2006-2010). 


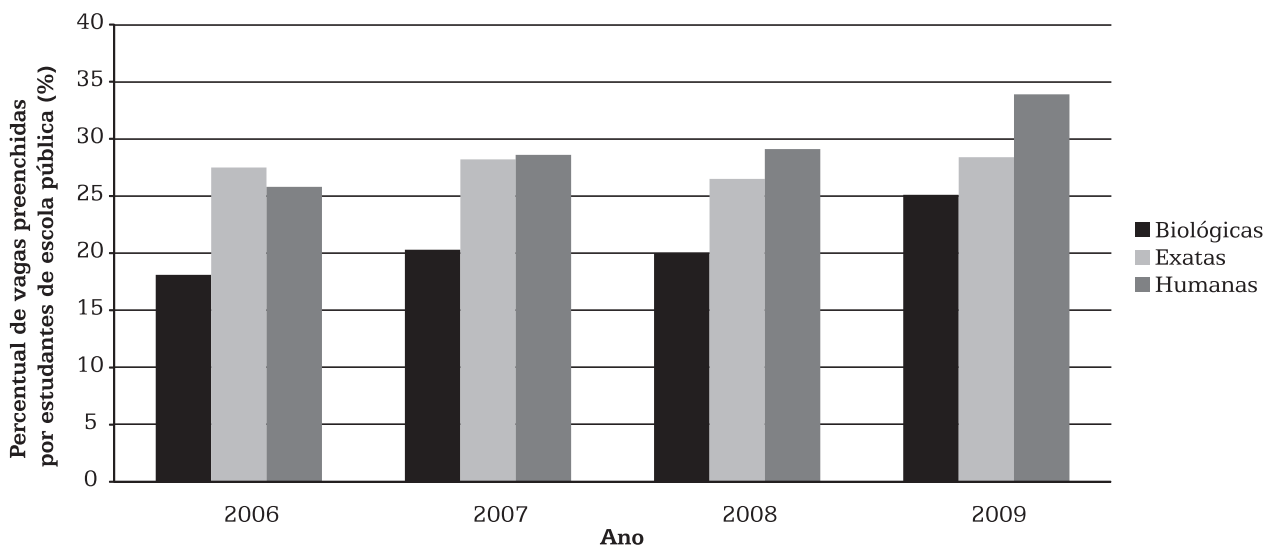

Gráfico 5 - Comparação entre os Percentuais de Vagas Preenchidas por Estudantes de Escola Pública em cada uma das Áreas do Conhecimento Valores Calculados em relação ao Total de Vagas Preenchidas - 2006-2009

Fonte: Pró-Reitoria de Graduação da USP (Gestão 2006-2010).

Quase a totalidade dos cursos da USP possui ingressantes oriundos de escola pública, mesmo os mais concorridos. Em 2009, 385 estudantes de escola pública ingressaram nos 15 cursos mais concorridos da USP, número 2,5 vezes maior do que os 152 estudantes que conseguiram ingressar nos 15 cursos mais concorridos em 2006 (ano que antecedeu a implantação do Inclusp). Trata-se de uma contribuição significativa do Inclusp na ampliação do número de estudantes de escola pública nos cursos de graduação mais concorridos da USP.

Por exemplo, nota-se um aumento expressivo no número de estudantes de escola pública ingressantes no curso de Medicina (campus São Paulo) em 2009 quando comparado ao ano que antecedeu a implantação do Inclusp. Em 2006, do conjunto de estudantes ingressantes no curso de Medicina, apenas nove haviam cursado todo o ensino médio em escola pública. Em 2009, esse número aumentou para 68, representando uma ampliação de aproximadamente $755 \%$.

No entanto, a ampliação do percentual de estudantes de escola pública nos cursos mais concorridos da USP não pode ser associado diretamente a um suposto efeito do bônus, já que a grande maioria desses estudantes teria conseguido a aprovação mesmo sem esse benefício, conforme constatado em análises simuladas que desconsidera a aplicação do sistema de pontuação acrescida. Assim, a ampliação do número de estudantes egressos do ensino médio público nos cursos de graduação mais concorridos da USP deve-se, sobretudo, a uma melhor preparação desses estudantes.

\section{Estudantes de baixa renda}

O perfil de renda familiar mensal dos candidatos inscritos no vestibular Fuvest em carreiras com curso USP é apresentado na Tabela 10. Verifica-se que, em todos os anos, o maior percentual de candidatos 
localiza-se em três faixas de renda familiar mensal (R\$500 a $\mathrm{R} \$ 1.500$, $\mathrm{R} \$ 1.500$ a $\mathrm{R} \$ 3.000$ e $\mathrm{R} \$ 3.000$ a $\mathrm{R} \$ 5.000)$, com pequenas variações em cada uma dessas faixas. Em 2007, ano de início do Inclusp, o percentual de candidatos com renda familiar até $\mathrm{R} \$ 3.000,00$ foi de 59,40\%, mostrando pouca variação no perfil socioeconômico do conjunto de candidatos inscritos no vestibular Fuvest. O mesmo comportamento foi observado nos anos posteriores, porém as faixas de renda familiar mensal foram definidas pelo número de salários mínimos (Tabela 11).

Tabela 10 - Distribuição Percentual de todos os Candidatos Inscritos no

Vestibular Fuvest (em Carreiras com Curso USP) em Diferentes Faixas de Renda Familiar Mensal, conforme Informações Declaradas pelos Candidatos no Questionário de Avaliação Socioeconômica - 2001-2007

\begin{tabular}{|c|c|c|c|c|c|c|c|}
\hline Ano & $\begin{array}{c}\text { Inferior } \\
a \\
\text { R\$500 } \\
(\%)\end{array}$ & $\begin{array}{c}R \$ 500 a \\
R \$ 1.500 \\
\quad(\%)\end{array}$ & $\begin{array}{c}\mathbf{R} \$ 1.500 \\
\mathrm{a} \\
\mathrm{R} \$ 3.000 \\
(\%)\end{array}$ & $\begin{array}{c}R \$ 3.000 \\
a \\
R \$ 5.000 \\
(\%)\end{array}$ & $\begin{array}{c}\mathbf{R} \$ 5.000 \\
\mathrm{a} \\
\mathbf{R} \$ 7.000 \\
(\%)\end{array}$ & $\begin{array}{c}\mathbf{R} \$ 7.000 \\
a \\
\mathbf{R} \$ 10.000 \\
(\%)\end{array}$ & $\begin{array}{c}\text { Superior } \\
\text { a } \\
\text { R\$10.000 } \\
(\%)\end{array}$ \\
\hline 2001 & 5,65 & 29,46 & 27,19 & 18,30 & 8,99 & 5,74 & 4,67 \\
\hline 2002 & 6,29 & 30,36 & 26,24 & 18,24 & 8,43 & 5,76 & 4,68 \\
\hline 2003 & 7,22 & 30,55 & 25,68 & 17,79 & 8,79 & 5,39 & 4,57 \\
\hline 2004 & 8,04 & 28,87 & 25,38 & 17,34 & 9,57 & 5,87 & 4,93 \\
\hline 2005 & 9,12 & 32,77 & 22,74 & 15,60 & 9,00 & 5,77 & 5,00 \\
\hline 2006 & 9,65 & 35,93 & 20,58 & 14,87 & 8,37 & 5,41 & 5,20 \\
\hline 2007 & 6,36 & 29,81 & 23,23 & 17,39 & 9,69 & 6,83 & 6,69 \\
\hline
\end{tabular}

Fonte: Pró-Reitoria de Graduação da USP (Gestão 2006-2010).

Obs.: Percentual calculado em relação ao número de respostas válidas para a questão n 17 do questionário socioeconômico da Fuvest assinaladas pelos candidatos inscritos no vestibular.

Comparando-se a renda familiar mensal dos candidatos inscritos no vestibular Fuvest no período de 2008 a 2010 (Tabela 11), observa-se um decréscimo na renda acima de 10 salários mínimos e abaixo de 2 salários mínimos e um aumento em faixas de renda intermediárias entre 3 e 10 salários mínimos.

Tabela 11 - Distribuição Percentual de Candidatos Inscritos no Vestibular Fuvest em Diferentes Faixas de Renda Familiar Mensal - 2008-2010

\begin{tabular}{|c|c|c|c|c|c|c|c|c|c|}
\hline Ano & $\begin{array}{c}\text { Inferior } \\
\text { a } 1 \text { SM } \\
(\%)\end{array}$ & $\begin{array}{c}1 \text { a } 2 \\
\text { SM } \\
(\%)\end{array}$ & $\begin{array}{c}2 \text { a } 3 \\
\text { SM } \\
(\%)\end{array}$ & $\begin{array}{c}3 \text { a } 5 \\
\text { SM } \\
(\%)\end{array}$ & $\begin{array}{c}5 \text { a } 7 \\
\text { SM } \\
(\%)\end{array}$ & $\begin{array}{c}7 \text { a } \\
10 \\
\text { SM } \\
(\%)\end{array}$ & $\begin{array}{c}10 \text { a } \\
14 \text { SM } \\
(\%)\end{array}$ & $\begin{array}{c}14 \text { a } \\
20 \\
\text { SM } \\
(\%)\end{array}$ & $\begin{array}{c}\text { Acima } \\
\text { de } 20 \\
\text { SM } \\
(\%)\end{array}$ \\
\hline 2008 & 1,72 & 10,16 & 10,75 & 18,09 & 13,12 & 13,60 & 12,75 & 9,04 & 10,78 \\
\hline 2009 & 1,70 & 9,83 & 11,81 & 18,41 & 13,51 & 13,85 & 12,04 & 8,67 & 10,18 \\
\hline 2010 & 1,29 & 6,83 & 11,00 & 20,05 & 16,09 & 14,79 & 11,52 & 8,34 & 10,09 \\
\hline
\end{tabular}

Fonte: Pró-Reitoria de Graduação da USP (Gestão 2006-2010).

Obs.: SM = Salário Mínimo. Percentual calculado em relação ao número de respostas válidas para a questão $n^{\circ} 17$ do questionário socioeconômico da Fuvest assinaladas pelos candidatos inscritos no vestibular. 
A diminuição de estudantes com renda familiar mensal acima de 10 salários mínimos também é observada no grupo de estudantes ingressantes na USP (Tabela 12). Nesse caso, porém, as variações são mais expressivas e significativas, indicando uma diminuição na renda dos candidatos em 2009 em comparação com o ano anterior.

\section{Tabela 12 - Distribuição Percentual de Estudantes Ingressantes na USP em Diferentes Faixas de Renda Familiar Mensal - 2008-2009}

\begin{tabular}{|c|c|c|c|c|c|c|c|c|c|}
\hline Ano & $\begin{array}{c}\text { Inferior } \\
\text { a } 1 \text { SM } \\
(\%)\end{array}$ & $\begin{array}{c}1 \text { a } 2 \\
\text { SM } \\
(\%)\end{array}$ & $\begin{array}{c}2 \text { a } 3 \\
\text { SM } \\
(\%)\end{array}$ & $\begin{array}{c}3 \text { a } 5 \\
\text { SM } \\
(\%)\end{array}$ & $\begin{array}{c}5 \text { a } 7 \\
\text { SM } \\
(\%)\end{array}$ & $\begin{array}{c}7 \text { a } 10 \\
\text { SM } \\
(\%)\end{array}$ & $\begin{array}{c}10 \text { a } \\
14 \text { SM } \\
(\%)\end{array}$ & $\begin{array}{c}14 \text { a } \\
20 \text { SIM } \\
(\%)\end{array}$ & $\begin{array}{c}\text { Acima } \\
\text { de } \\
20 \mathrm{SM} \\
(\%)\end{array}$ \\
\hline 2008 & 0,73 & 4,70 & 7,19 & 15,99 & 13,54 & 15,90 & 16,22 & 11,38 & 14,35 \\
\hline 2009 & 0,88 & 5,29 & 8,41 & 17,33 & 15,03 & 15,87 & 14,15 & 10,31 & 12,73 \\
\hline
\end{tabular}

Fonte: Pró-Reitoria de Graduação da USP (Gestão 2006-2010).

Obs.: SM = Salário Mínimo. Percentual calculado em relação ao número de respostas válidas para a questão n 17 do questionário socioeconômico da Fuvest assinaladas pelos estudantes ingressantes na USP.

No caso do conjunto de estudantes oriundos de escola pública que ingressaram na USP nos anos de 2008 e 2009, observou-se (Tabela 13) variações mais concentradas em algumas faixas de renda específicas, com reduções expressivas nas faixas entre 7 e 14 salários mínimos e ampliação mais acentuada nas faixas entre 2 e 5 salários mínimos, indicando mudança no perfil de renda familiar nesse conjunto de estudantes, no qual 74,81\% apresentam renda familiar mensal inferior a 7 salários mínimos. Assim, ao centrar seu foco em estudantes de escola pública, o Inclusp tem mostrado contribuir também para a inclusão de estudantes de condições socioeconômicas menos favorecidas. Esse resultado mostra-se ainda mais relevante se considerarmos que no período em questão o Brasil atravessou uma fase muito positiva em relação a sua economia, o que possibilitou a melhoria na renda da população brasileira.

Tabela 13 - Distribuição Percentual de Estudantes de Escola Pública Ingressantes na USP em Diferentes Faixas de Renda Familiar Mensal - 2008-2009

\begin{tabular}{|c|c|c|c|c|c|c|c|c|c|}
\hline Ano & $\begin{array}{c}\text { Inferior } \\
\text { a } 1 \text { SM } \\
(\%)\end{array}$ & $\begin{array}{c}1 \text { a } 2 \\
\text { SM } \\
(\%)\end{array}$ & $\begin{array}{c}2 \text { a } 3 \\
\text { SM } \\
(\%)\end{array}$ & $\begin{array}{c}3 \text { a } 5 \\
\text { SM } \\
(\%)\end{array}$ & $\begin{array}{c}5 \text { a } 7 \\
\text { SM } \\
(\%)\end{array}$ & $\begin{array}{c}7 \text { a } 10 \\
\text { SM } \\
(\%)\end{array}$ & $\begin{array}{c}10 \mathrm{a} \\
14 \mathrm{SM} \\
(\%)\end{array}$ & $\begin{array}{c}14 \mathrm{a} \\
20 \mathrm{SM} \\
(\%)\end{array}$ & $\begin{array}{c}\text { Acima } \\
\text { de } \\
20 \mathrm{SM} \\
(\%)\end{array}$ \\
\hline 2008 & 1,50 & 12,75 & 15,25 & 26,24 & 15,25 & 13,35 & 8,82 & 3,85 & 2,99 \\
\hline 2009 & 1,64 & 12,27 & 17,52 & 27,67 & 15,72 & 11,66 & 7,21 & 4,06 & 2,25 \\
\hline
\end{tabular}

Fonte: Pró-Reitoria de Graduação da USP (Gestão 2006-2010).

Obs.: SM = Salário Mínimo. Percentual calculado em relação ao número de respostas válidas para a questão n 17 do questionário socioeconômico da Fuvest assinaladas pelos estudantes de escola pública ingressantes na USP. 


\section{Estudantes negros}

O percentual de candidatos negros inscritos no vestibular da USP diminuiu no período de 2006 a 2010 (Gráfico 6), observando-se uma redução significativa de 8,02\% nesse período. Evidentemente, o aumento de ingressantes provenientes do ensino público, negros ou não, depende diretamente do número de candidatos que se inscrevem no vestibular, pois o aumento no número de inscritos amplia a probabilidade de ingresso desses candidatos na USP.

Considerando o conjunto dos candidatos que declararam a sua cor no questionário socioeconômico, os negros representavam 24,23\% dos inscritos em 2006, 20,98\% em 2007, 19,69\% em 2008, 18,31\% em 2009 e 16,21\% em 2010 (ver Gráfico 6). Verifica-se, portanto, que a porcentagem de negros inscritos no vestibular diminuiu no período em questão, alcançando $16,21 \%$, enquanto que o percentual de negros no Estado de São Paulo é de 30,9\% (IBGE - Pesquisa Nacional por Amostra de Domicílios - Pnad 2005).

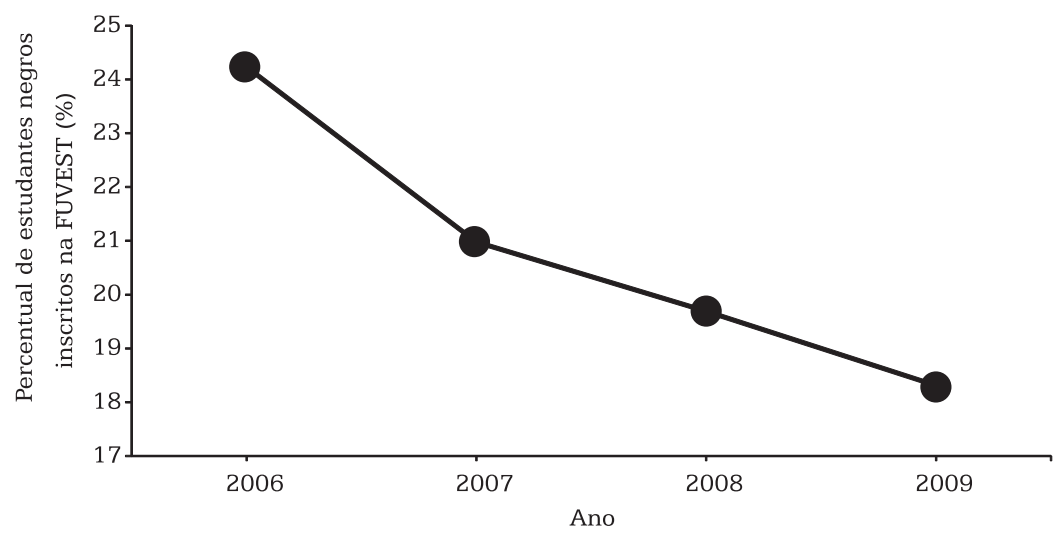
Gráfico 6 - Diminuição do Percentual de Candidatos Negros Inscritos no
Vestibular Fuvest - 2006-2010

Fonte: Pró-Reitoria de Graduação da USP (Gestão 2006-2010).

Esse comportamento assemelha-se à diminuição do percentual de candidatos inscritos oriundos de escola pública no mesmo período (Tabela 3). A semelhança entre esses dois grupos deve-se ao fato de a maioria dos candidatos negros ser oriunda de escolas públicas. Em 2009, por exemplo, 60,9\% dos candidatos negros inscritos no vestibular Fuvest, em carreiras com curso USP, declararam ter cursado todo o ensino médio em escola pública. Em 2010, esse valor foi de 49,75\%.

Em oposição à tendência observada no conjunto dos inscritos, o percentual de candidatos negros ingressantes na USP aumentou no período de 2006 a 2009 (Tabela 14), alcançando o maior percentual $(14,26 \%)$ registrado até hoje na USP desde quando a Fuvest passou a utilizar o questionário de avaliação socioeconômica como instrumento para a identificação da cor dos candidatos. 
Comparando-se os percentuais de estudantes negros ingressantes na USP com os percentuais calculados a partir de uma situação simulada que desconsidera os bônus praticados no período de 2007 a 2009, observa-se um impacto direto do Inclusp no aumento observado, ampliando em até 1,8\% o percentual de negros na USP em 2009 (Gráfico 7).

Tabela 14 - Distribuição Percentual dos Estudantes Ingressantes na USP em Relação a sua Cor de Pele - 2006-2009

\begin{tabular}{|c|c|c|c|c|c|c|}
\hline Ano & $\begin{array}{c}\text { Branca } \\
\mathbf{( \% )}\end{array}$ & $\begin{array}{c}\text { Amarela } \\
\mathbf{( \% )}\end{array}$ & $\begin{array}{c}\text { Indígena } \\
\mathbf{( \% )}\end{array}$ & $\begin{array}{c}\text { Preta } \\
\mathbf{( \% )}\end{array}$ & $\begin{array}{c}\text { Parda } \\
\mathbf{( \% )}\end{array}$ & $\begin{array}{c}\text { Negros } \\
\text { (Preta }+ \\
\text { Parda) } \\
\text { (\%) }\end{array}$ \\
\hline 2001 & 79,24 & 12,14 & 0,40 & 1,31 & 6,92 & 8,23 \\
\hline 2002 & 79,28 & 11,96 & 0,41 & 1,49 & 8,28 & 9,14 \\
\hline 2003 & 79,66 & 10,18 & 0,41 & 1,69 & 8,06 & 9,75 \\
\hline 2004 & 79,65 & 9,15 & 0,31 & 1,77 & 9,12 & 10,89 \\
\hline 2005 & 76,60 & 10,02 & 0,37 & 1,79 & 11,23 & 13,02 \\
\hline 2006 & 77,06 & 10,07 & 0,40 & 1,76 & 10,72 & 12,47 \\
\hline 2007 & 76,57 & 9,62 & 0,45 & 2,11 & 11,26 & 13,37 \\
\hline 2008 & 77,48 & 8,60 & 0,24 & 2,17 & 11,51 & 13,69 \\
\hline 2009 & 77,05 & 8,43 & 0,26 & 2,61 & 11,65 & 14,26 \\
\hline
\end{tabular}

Fonte: Pró-Reitoria de Graduação da USP (Gestão 2006-2010).

Obs.: Percentual calculado em relação ao número de respostas válidas para a questão nº 17 do questionário socioeconômico da Fuvest assinaladas pelos estudantes ingressantes na USP.

Um fator que contribuiu para a elevação do percentual de estudantes negros em relação ao total de ingressantes foi o aumento do número de candidatos negros no conjunto de ingressantes oriundos de escola pública, que passou de 22,87\% em 2006 para 25,13\% em 2009.

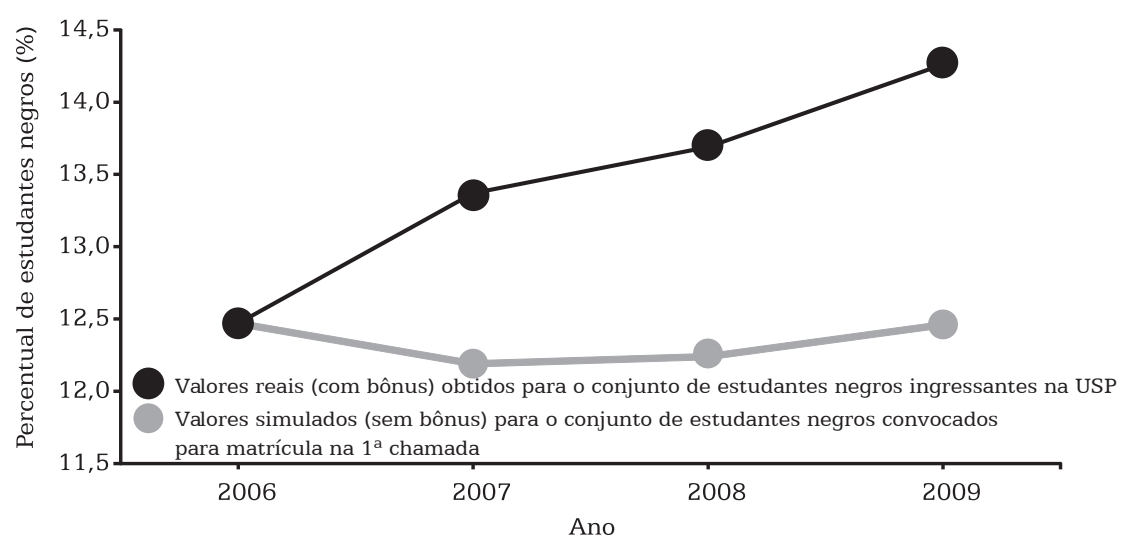

Gráfico 7 - Impacto do Sistema de Pontuação Acrescida no Percentual de Estudantes Negros Ingressantes na USP - 2006-2009

Fonte: Pró-Reitoria de Graduação da USP (Gestão 2006-2010). 
$\mathrm{Na}$ análise da distribuição dos candidatos negros inscritos no vestibular Fuvest em carreiras com curso USP (Tabela 15), no período de 2001 a 2007, observou-se que mais de $82 \%$ dos estudantes pertencentes a esse grupo possuem baixo nível socioeconômico, com faixas de renda familiar mensal inferiores a $\mathrm{R} \$ 3.000,00$. Na mesma direção, a análise dos dados de 2008 e 2009 revelou que 86,72\% e 86,95\%, respectivamente, declararam possuir renda familiar mensal inferior a 7 salários mínimos. No entanto, no ano de 2010, esse percentual caiu para $75,15 \%$

Quando considerado o conjunto de ingressantes, o percentual de estudantes negros nas faixas de renda mais baixas (até 7 salários mínimos) nos anos de 2008 e 2009 foi de 61,17\% e 65,34\%, respectivamente. Também se observa (Tabela 16) diminuição no percentual de estudantes negros com renda nas faixas de 7 a 20 salários mínimos e aumento significativo do percentual de estudantes negros com renda entre 2 a 7 salários mínimos. Esses resultados indicam uma mudança no perfil de renda familiar mensal dos estudantes negros ingressantes na USP em 2009 em comparação com o ano anterior.

Tabela 15 - Distribuição Percentual de Candidatos Negros Inscritos no Vestibular Fuvest em Diferentes Faixas de Renda Familiar Mensal 2001-2007

\begin{tabular}{|c|c|c|c|c|c|c|c|}
\hline Ano & $\begin{array}{c}\text { Inferior } \\
\text { a R } \$ 500 \\
\text { (\%) }\end{array}$ & $\begin{array}{c}R \$ 500 a \\
R \$ 1.500 \\
\quad(\%)\end{array}$ & $\begin{array}{c}R \$ 1.500 \\
a \\
R \$ 3.000 \\
(\%)\end{array}$ & $\begin{array}{c}\mathrm{R} \$ 3.000 \\
a \\
\mathrm{R} \$ 5.000 \\
(\%)\end{array}$ & $\begin{array}{c}\mathrm{R} \$ 5.000 \\
a \\
\mathrm{R} \$ 7.000 \\
(\%)\end{array}$ & $\begin{array}{c}\mathrm{R} \$ 7.000 \\
\mathrm{a} \\
\mathrm{R} \$ 10.000 \\
(\%)\end{array}$ & $\begin{array}{c}\text { Superior } \\
\text { a } \\
\text { R } \$ 10.000 \\
\text { (\%) }\end{array}$ \\
\hline 2001 & 14,61 & 48,05 & 22,17 & 8,97 & 3,28 & 1,75 & 1,17 \\
\hline 2002 & 15,53 & 48,63 & 20,90 & 8,97 & 2,96 & 1,81 & 1,20 \\
\hline 2003 & 16,92 & 47,81 & 19,82 & 8,65 & 3,62 & 1,84 & 1,34 \\
\hline 2004 & 18,87 & 44,64 & 20,24 & 8,75 & 4,03 & 1,98 & 1,49 \\
\hline 2005 & 19,30 & 50,18 & 16,90 & 7,12 & 3,24 & 1,86 & 1,39 \\
\hline 2006 & 19,31 & 54,22 & 14,70 & 6,35 & 2,70 & 1,55 & 1,17 \\
\hline 2007 & 14,12 & 50,17 & 19,12 & 8,67 & 3,76 & 2,34 & 1,82 \\
\hline
\end{tabular}

Fonte: Pró-Reitoria de Graduação da USP (Gestão 2006-2010).

Obs.: Percentual calculado em relação ao número de respostas válidas para a questão nº 17 do questionário socioeconômico da Fuvest assinaladas pelos candidatos negros inscritos no vestibular.

O número absoluto de estudantes negros que cursaram integralmente o ensino médio na rede pública de ensino e que ingressaram na USP em 2007 foi de 660, um aumento de 18,5\% em comparação aos 557 do ano de 2006, que representavam 22,9\% do total de ingressantes oriundos do ensino público, percentual inferior aos 24,6\% em 2007, 23,4\% em 2008 e $24,89 \%$ em 2009. É importante salientar que, do total de estudantes negros ingressantes na USP em 2007 e 2008, quase metade (49,1\% em 2007, 45,5\% em 2008 e 53,12\% em 2009) eram oriundos do ensino médio público. 
Tabela 16 - Distribuição Percentual de Candidatos Negros Ingressantes no Vestibular Fuvest em Diferentes Faixas de Renda Familiar Mensal $-2008-2009$

\begin{tabular}{|c|c|c|c|c|c|c|c|c|c|}
\hline Ano & $\begin{array}{c}\text { Inferior } \\
\text { a } 1 \text { SM } \\
\text { (\%) }\end{array}$ & $\begin{array}{c}1 \text { a } 2 \\
\text { SM } \\
(\%)\end{array}$ & $\begin{array}{c}2 \text { a } 3 \\
\text { SM } \\
(\%)\end{array}$ & $\begin{array}{c}3 \text { a } 5 \\
\text { SM } \\
(\%)\end{array}$ & $\begin{array}{c}5 \text { a } 7 \\
\text { SM } \\
(\%)\end{array}$ & $\begin{array}{c}7 \text { a } 10 \\
\text { SM } \\
(\%)\end{array}$ & $\begin{array}{c}10 \mathrm{a} \\
14 \mathrm{SM} \\
(\%)\end{array}$ & $\begin{array}{c}14 \mathrm{a} \\
20 \mathrm{SM} \\
(\%)\end{array}$ & $\begin{array}{c}\text { Acima } \\
\text { de } 20 \\
\text { SM } \\
(\%)\end{array}$ \\
\hline 08 & 1,72 & , 49 & 12,28 & 1,97 & 13,71 & 13,50 & 11,06 & 7,75 & 6,53 \\
\hline 2009 & 1,64 & 11,55 & 14,76 & 22,90 & 14,49 & 12,65 & 9,91 & 6,90 & 5,19 \\
\hline
\end{tabular}

Fonte: Pró-Reitoria de Graduação da USP (Gestão 2006-2010).

Obs.: SM = Salário Mínimo. Percentual calculado em relação ao número de respostas válidas para a questão $\mathrm{n}^{\circ} 17$ do questionário socioeconômico da Fuvest assinaladas pelos candidatos negros ingressantes na USP.

A análise do conjunto dos resultados obtidos permite concluir que, mesmo com o decréscimo do percentual de estudantes negros (pretos ou pardos) no grupo de inscritos do vestibular da USP, as ações do Inclusp possibilitaram a ampliação contínua do percentual desses estudantes no conjunto de ingressantes nos cursos da USP em patamares nunca antes alcançados.

\section{Desempenho acadêmico dos estudantes Inclusp}

Analisando-se os únicos dados disponíveis de desempenho dos ingressantes na USP oriundos da escola pública, observamos que, em 2007, as médias dos ingressantes Inclusp $(6,3)$ ficaram ligeiramente acima da média da Universidade (6,2). Dos 118 cursos oferecidos na USP, a média dos ingressantes Inclusp foi igual à média geral em oito cursos ${ }^{2}$ ou superior em 54 cursos, $^{3}$ ou seja, em 64 dos 118 cursos da USP os ingressantes Inclusp tiveram média superior ou igual à média USP, ilustrando que a ampliação no ingresso por meio do sistema de bonificação não compromete a qualidade do conjunto de estudantes selecionados.

\section{Considerações finais}

A análise dos resultados referentes ao período de 2001 a 2009 permite afirmar que o objetivo do Inclusp de ampliar progressivamente os percentuais de estudantes egressos do ensino médio público na USP foi atingido, contribuindo também para a ampliação do ingresso de estudantes de baixa renda e de estudantes negros, sem qualquer comprometimento do critério de mérito acadêmico da Universidade.

Em 2010, porém, o efeito do sistema de pontuação acrescida não foi suficiente para neutralizar a crescente diminuição da participação de estudantes de escola pública no vestibular Fuvest, fenômeno que já se evidenciava desde 2006. Esse diagnóstico sinaliza a necessidade de maior aproximação entre a USP e as escolas públicas por meio da ampliação de
${ }^{2}$ Medicina, Odontologia, Direito, Ciências Econômicas, Filosofia, Arquitetura e Urbanismo, na capital, e Administração, em Ribeirão Preto.

3 Alguns exemplos: na capital - Medicina Veterinária, Química, Matemática Aplicada e Computacional, Oceanografia, Geofísica, História. No interior: Medicina, Odontologia, Química, Farmácia (Ribeirão Preto); Engenharia (oito cursos), Ciências da Computação, Física (São Carlos); Escola Superior de Agricultura Luiz de Queiroz - Esalq (quatro cursos); Engenharia de Alimentos (Pirassununga); Odontologia (Bauru). 
programas, tais como o Pasusp e o Programa Embaixadores da USP, bem como a necessidade de se criar novos programas e estratégias de publicização mais efetivas junto à sociedade, buscando atrair mais estudantes do ensino médio público para o vestibular Fuvest por meio da divulgação das vantagens de se estudar numa universidade pública, gratuita e de qualidade.

\section{Referências bibliográficas}

COULON, Alain. A condição de estudante: a entrada na vida universitária. Salvador: Edufba, 2008.

EZCURRA, Ana María. Diagnóstico preliminar de las dificultades de los alumnos de primer ingreso a la educación superior. Perfiles Educativos, v. 27, n. 107, p. 118-133, 2005. Disponível em: <http://redalyc. uaemex.mx/redalyc/src/inicio/ArtPdfRed.jsp?iCve=13210706>. Acesso em: 16 jan. 2011.

Los estudiantes de nuevo ingreso: democratización y responsabilidad de las instituciones universitarias. In: PIMENTA, Selma Garrido; ALMEIDA, Maria Isabel de (Orgs.). Pedagogia Universitária. São Paulo: EDUSP, 2009. p. 91-128. Disponível em: < http://www.prg. usp.br/site/images/stories/arquivos/ana_maria_scurra_caderno_2.pdf $>$.

GUIMARÃES, Antonio Sérgio A. Contexto histórico-ideológico do desenvolvimento das ações afirmativas no Brasil. Comunicação ao Seminário Internacional "Ações afirmativas nas políticas educacionais brasileiras: o contexto pós-Durban", 2005. Disponível em <http://www. fflch.usp.br/sociologia/asag/> . Acesso em: 13 out. 2007.

INSTITUTO BRASILEIRO DE GEOGRAFIA E ESTATÍSTICA (IBGE). Pesquisa Nacional por Amostra de Domicílios (Pnad). 2005. Disponível em: <http://www.ibge.gov.br/home/estatistica/populacao/ trabalhoerendimento/pnad2005/sintesepnad2005.pdf $>$.

LAHIRE, Bernard. Sucesso escolar nos meios populares: as razões do improvável. São Paulo: Ática, 1997.

MOEHLECKE, Sabrina. Ação afirmativa: história e debates no Brasil. Cadernos de Pesquisa, n. 117, p. 197-217, nov. 2002. Disponível em: <http://www.scielo.br/pdf/cp/n117/15559>.

OLIVEIRA, Romualdo Portela; SOUSA, Sandra Maria Zákia (coord.). Acompanhamento da trajetória escolar dos alunos da Universidade de São Paulo: ingressantes de 1995 a 1998. São Paulo: Pró-Reitoria de Graduação da USP, 2004. 
PIMENTA, Selma G.; ALMEIDA, Maria Isabel de; OLIVEIRA, Maria Amélia de Campos (Orgs.). A graduação na Universidade de São Paulo: análise de uma gestão (2006 - 2009). São Paulo: Pró-reitoria de Graduação da USP, 2010. CD ROM Disponível em: <http://www5.usp.br/>.

PINTO, José Marcelino de Rezende. O acesso à educação superior no Brasil. Educação \& Sociedade, Campinas, v. 25, n. 88, p. 727-756, out. 2004.

Disponível em: <http://www.scielo.br/pdf/es/v25n88/a05v2588.pdf>.

Mauricio dos Santos Matos, doutor em Ciências pela Universidade de São Paulo (USP), é professor do Departamento de Educação, Informação e Comunicação da Faculdade de Filosofia, Ciências e Letras de Ribeirão Preto da USP.

maumatos@ffclrp.usp.br

Selma Garrido Pimenta, doutora em Educação: Filosofia da Educação pela Pontifícia Universidade Católica de São Paulo (PUC-SP), é professora titular da Faculdade de Educação da Universidade de São Paulo (USP).

sgpiment@usp.br

Maria Isabel de Almeida, doutora em Didática pela Faculdade de Educação da Universidade de São Paulo (Feusp), é professora do Departamento de Metodologias do Ensino e Educação Comparada da Feusp. mialmei@usp.br

Maria Amélia de Campos Oliveira, doutora em Enfermagem pela Universidade de São Paulo, é professora titular do Departamento de Enfermagem em Saúde Coletiva da Escola de Enfermagem da Universidade de São Paulo (USP).

macampos@usp.br

Recebido em 25 de abril de 2011.

Aprovado em 18 de abril de 2012. 